\title{
Lo Gauchesco en el Teatro Argentino, Antes y Después de Martin Fierro
}

A partir del último cuarto del siglo XviI, en el género dramático aparecen las más tempranas expresiones de literatura gauchesca rioplatense. Durante el siglo $\mathrm{xIx}$, en distintas especies épicas o líricas, dicha modalidad literaria desarrolla un itinerario creador, culminado en 1872 con Martin Fierro. Pocos años más tarde, en 1884, Juan Moreira -un folletín de Eduardo Gutiérrez aparecido en varias entregas de $L_{a}$ Patria Argentina, durante 1879- es trasvasado genéricamente para su insetción pantomímica en un espectáculo circense. De él resurgirá, con nueva y definida personalidad, el teatro nacional argentino, tras una etapa en la cual el teatro gauchesco adquirirá fundamental gravitación. El propio poema de Hernándéz será adaptado para su exhibición teatral. Simultáneamente, los saltimbanquis se convertirán en actores $\mathrm{y}$, abandonando el circo, se instalarán en los teatros. Sin embargo, al pasar del picadero al escenario "a la italiana", la dramática gauchesca paulatinamente perderá vigencia, para dar paso a un teatro "rural" y a un teatro "ciudadano", ambos atentos a corrientes y orientaciones de extracción foránea.

Este sintético enunciado preliminar encierra, no obstante, el planteo de algunas cuestiones concernientes, ambivalentemente, a la historia literaria y a la historia teatral argentinas, a saber: I) ¿Qué influencias proyectó el precedente dramático sobre otras manifestaciones de literatura gauchesca? ¿Cómo fue el teatro gauchesco anterior a Juan Moreira? II) ¿Qué significó Judn Moreira en el teatro argentino y qué proceso promovió? III) ¿Qué suerte corrió Martín Fierro en el teatro? ¿Cuál fue su incidencia en el posterior teatro gauchesco? IV) ¿Cómo y pot qué el teatro gauchesco evolucionó?

La consideración y desarrollo de estos planteos delinean la estructura del presente ensayo, que condensa información y observaciones expuestas anteriormente en varios de mis libros. ${ }^{1}$

1 Cfr.: Esquema de la literatura dramática argentina (Buenos Aires, Instituto de historia del Teatro Americano, 1950), El circo criollo (Buenos Aires, Lajoua- 
El amor de la estanciera, sainete representado en el "Teatro de la Ranchería" entre 1792 y 1793, constituye la más antigua muestra, completa y unitaria, de literatura gauchesca conocida, en el sentido estricto de lo que se entiende por gauchesco. Este origen teatral parece sobrevivir en manifestaciones posteriores, aun en los géneros no dramáticos.

Como se sabe, a lo largo del siglo xix, lo gauchesco se desarrolla principalmente en creaciones líricas o épicas y mantiene algo así como una omnipresente reminiscencia de aquel origen teatral, manifiesta en la letra y coreografia de canciones y danzas, como el "cielito"; en el canto alterno payadoresco, las formas directas de diálogo entre personas presentes o de "epistolas al caso", cambiadas entre personajes distantes; en las "relaciones" testimoniales y el mecanismo dialéctico de "consejos a los jóvenes". Tal reminiscencia, en las formas épicas, se relaciona con los modos del intercambio de noticias entre personajes de extracción popular; con agudezas, sátitas, críticas irónicas y quejas frente a determinadas condiciones sociopolíticas; con la visión de costumbres y problemas ciudadanos a través de una óptica campesina. Conecta seres imaginarios o reales que, emergidos literariamente por vía narrativa o dialogal, entrañan latente posibilidad de aprovechamiento escénico.

Dentro del panorama conjunto de la literatura gauchesca, los ejemplos de dialogantes y payadores abundan: "Chano y Contreras", en Bartolomé Hidalgo; "Corro y El Viejo", "Badanas y Papanata", en Juan Gualberto Godoy; "Chuche Gestos y Antuco Gramajo", en Luis Pérez; "Anastasio el Pollo y Laguna", en Estanislao del Campo; "Rufo Tolosa y Santos Vega", "Martín Sayago y Paulino Lucero", "Contreras y Barragán", "Contreras y Salvador Antuco", "Luciano Oliva y Morales", "Jacinto Amores y Simón Peñalva", en Hilario Ascasubi; "Lucero y Trejo", en Manuel Araucho; "Fierro y Cruz", en el poema de Hernández. Se trata, casi siempre, de amistad entre varones, conectados por circunstancias azarosas. Intercambian referencias de vicisitudes y aventuras, apreciaciones sociales y políticas, quejas e impresiones.

Otro tanto ocurre con los envíos epistolares, cruzados por vía periodística, que envuelven forma particular de relación, diálogo potencial $\mathrm{y}$, por ende, también posibilidad de trasponer su latencia dramática. Cabe

ne S. R. Ltda. 1953), Centurias del circo criollo (Buenos Aires, Ed. Perrot, 1959), Sociología del teatro argentino (Buenos Aires, Nova, 1963), Literatura dramática argentina 1717-1967 (Buenos Aires, Pleamar, 1968), Teatro argentino pre'moreirista (Buenos Aires, Plus Ultra, 1969), "Martín Fierro y el teatro gauchesco" (en el volumen de homenaje: Marinn Fierro, in siglo, Buenos Aires, Editorial Xerox, 1972). 
recordar, entre muchas otras, las "Cartas del Gaucho de San Nicolás y las de "El Gaucho de Pergamino", dirigidas al periódico El Corazero, ambas de Juan Gualberto Godoy; las de Luis Pérez, aparecidas en El Gaucho; las de "Jacinto Lugones a Pancho Lugares" y de "Pancho Lugares a su mujer Chanonga", también de Luis Pérez; la anónima "Carta de un Gaucho de Tucumán a otro Gaucho de Córdoba"; la nutrida serie de correspondencia gaucha debida a la pluma de Hilario Ascasubi. Sin omitir que, en los días rivadavianos, el Padre Castañeda atacaba a los enciclopedistas por medio de un periódico gauchesco que él redactaba; y que, durante la época de Rosas, hubo varios otros de la misma índole al servicio de los intereses de la campaña.

Por otra parte, además de las concomitantes razones relacionadas con aquel ancestro teatral, la literatura gauchesca aparece realizada, desde sus ejercicios más remotos, en dos vertientes netamente diferenciables: una realista y pintoresca, de matiz costumbrista y atractivo "color local"; otra de protesta, con intención política o social, como algunos "Cielos" de Bartolomé Hidalgo o el Díalogo Patriótico Interesante del mismo, culminada en Martín Fierro y continuada en la línea del teatro gauchesco y rural posterior. Sin embargo, el teatro gauchesco primitivo, hasta 1881 - fecha de la edición de Solané, de Francisco Fernández-, scultivó sólo la primera de las direcciones antedichas, mostrando algunas notas burlescas en la cuerda pintoresca; aspectos de intención documental y de exploración del sentir popular, en la realista.

Lo gauchesco en el teatro argentino abarca tres etapas bien diferenciadas: la primitiva, desde 1792 a 1884; la de su vida en el picadero circense, que abarca desde 1884 a 1896; y la de su evolución hacia el teatro rural, que se desarrolla con alternativas diversas, hasta el presente.

La etapa primitiva arranca con El amor de la estanciera, sainete anó. nimo conservado en un manuscrito, varios de cuyos folios están copiados en papeles sellados con la impromta: "Carolus III. D. G. Hispaniarum Rex: valga para el reinado de S. M. St. D. Carlos IV.-Seis reales.Sello segundo, seis reales.-año de mil setecientos noventa y uno", la cual permite conjeturar la fecha de origen. Fue estudiado y publicado por Mariano G. Bosch, en edición de $\mathrm{l}_{a}$ " "Sección Documentos" del Instituto de Literatura Argentina de la Universidad de Buenos Aires; y reproducido, más tarde, en el volumen Teatro gauchesco primitivo, organizado por Juan Carlos Ghiano para la Editorial Losange, de Argentina.

El sainete reproduce un incidente campesino en el que un matrimonio viejo, Cancho y Chepa, desacuerda en el auspicio de marido para su hija Chepa. El padre se inclina por Juan Perucho, gaucho joven, diestro en las faenas ganaderas, parco de palabras, algo hosco. La madre, por Marcos 
Figueira, portugués fanfarrón, continuamente ridiculizado. Chepa vacila entre ambos candidatos, pero finalmente acepta a Juan Perucho y culmina el ridículo de Marcos, obligado a cocinar el almuerzo de bodas.

El lenguaje del sainete - estudiado por Amelia Sánchez Garrido, en Indagación de lo argentino ${ }^{2}$ _ ofrece un verdadero documento de realidad gauchesca, sobre todo en las abundantes expresiones interjectivas y ternos, en la peculiar deformación fonética. Lo mismo ocurre con las referencias a tareas rurales, menciones de pelajes equinos y marcas de ganadería. Pero lo verdaderamente precursor estriba en la captación de la idiosincrasia gaucha, tanto en la conducta patriarcal de Cancho, el machismo de los varones criollos y la derrota del extranjero obligado a una tarea femenina, como en el tono cazurro, la misantropía y parquedad de Juancho Perucho. "La pieza - ha opinado Ernesto Morales - dentro de la parquedad de su argumentò y la modestia de sus octosílabos, teniendo en cuenta la época de su representación, dos lustros antes de Mayo de 1810, tiene un valor histórico. Juancho representa el elemento nativo; el portugués lo europeo; el padre es una fuerza renovadora y la conservadora es la madre... Triunfa el espíritu nuevo... Este espíritu de la tierra, renovador de lo establecido, va pronto a hacerse voz de poetas..."3 Además estos elementos -reacción frente al extranjero, sentido de la tierra y de la libertad, conflicto contra lo establecido por fuerzas distantes- serán constantes de toda la literatura gauchesca posterior.

Las bodas de Cbivico y Pancha, piececilla estrenada en 1823, marca la continuidad teatral del tema gauchesco de intención pintoresca y realista en la escena argentina. También conservado en un manuscrito anónimo, correspondió al Instituto de Literatura Argentina (U.N.B.A.) su exhumación y primera edición, en 1925. Representado en diversas ocasiones, entre 1823 y 1850 , al cabo de ellas su texto sufrió modificaciones y añadiduras. Se trata en él, como en El amor de la estanciera, de la celebración de una boda; en ambos la comida nupcial apoya pintoresquismos, entremezclando personajes de la ciudad y campesinos. Durante la ceremonia, el padre de la novia da consejos prácticos a los jóvenes esposos, del tipo de los que aparecerán luego en boca de Vizcacha y de Fierro. Hay referencias a lugares urbanos próximos y, entre los añadidos, se incluye una típica "relación" de festejos ciudadanos narrados con óptica gauchesca por el personaje Chingolo, que recuerda aquella otra Relación que bace el gaucbo Ramón Contreras a Jacinto Cbano de todo lo que vio

2 Amelia Sánchez Garrido: Indagación de lo argentino. Buenos Aires, Ediciones Culturales Argentinas, 1967.

a Ernesto Morales: Historia del keatro argentino. Buenos Aires, Lautaro, 1944. (pp. 38, 39). 
en las Fiestas Mayas en Buenos Aires, en el año 1822. Además, por la mención que Chingolo hace de su visita al teatro, durante la representación de la comedia de magia $\mathrm{El}$ diablo predicador, parece antecedente de Fausto, de Estanislao del Campo.

Durante los días de la guerra con Brasil se le agregaron coplas alusivas a episodios de la misma. Matilde Levy, en la monografía "La Oda del Bagre Sapo"," documenta cómo, en 1826, se intercaló en el sainete dicha parodia, de tipo épico-burlesco; e intenta probar estilísticamente la posibilidad de que el autor oculto tras el seudónimo de "Bagre Sapo" haya sido Juan Cruz Varela.

Para el ya citado Ernesto Morales, en Las bodas de Cbivico y Pan$c b a$, " los personajes y el cuadro de costumbres poseen realidad y colorido. La vida circula por él, y para nosotros, como historia, y aun como teatro, tiene más importancia que muchas obras con pretensiones literarias, pero producto de la imitación y que resultan un trasplante'. 5

Las historias del teatro argentino consignan referencias de otras piezas gauchescas representadas posteriormente, como $U n$ día en Barracas, fin de fiesta anónimo estrenado hacia 1850 y El goucho en Buenos Aires (1857), de Estanislao del Campo, cuyos libretos no son localizables. Sólo en 1881, al reeditar Francisco Fernández sus Obras dramaticas, incluye entre ellas Solanié, drama de carácter gauchesco que aporta el anticipo de una nueva dirección que asumirá el teatro de esta índole.

Solané, escrito en Concordia (Entre Ríos), a fines de 1872, a poco de la aparición de la Primera Parte de Martín Fierro y rotulado como "drama histórico contemporáneo" con alguna justificación, fue reeditado por el Instituto de Literatura Argentina, en 1925, precedido por un volumen complementario en el cual Ricardo Rojas estudió personalidad y obra del autor.

Como Juan Moreira, Jerónimo Solané fue persona histórica. Delincuentes ambos, idealizados, románticamente por la imaginación popular y ciertas crónicas periodísticas. Según Rafael Barreda, Solané era chileno, hijo de un francés y de una araucana. Empezó estudios de medicina, que debió abandonar por dificultades económicas.' "Llegó a los pagos de Tandil a propagar su fama de curandero, siguiéronlo muchos y el orgullo desenfrenado de aquel miserable llegó a extremo tal que una noche convenció a sus acólitos de que era necesario dar muerte a los extranjeros y a los que no creían en su ciencia divina. La noche del 31 de diciembre de 1871 consumaron el asalto a muchas personas: unos compañeros

4 Matilde Levy: "La Oda del Bagre Sapo" (En Boletin de Estudios de Teatro N. 30. Buenos Aires, Instituto Nacional de Estudios de Teatro, 1960).

5 Ernesto Morales: obra citada (pp. 101, 102). 
de Solané fueron condenados a muerte y la culpabilidad de éste no pudo probarse. Pero el pago de Tandil se hizo justicia por sus propias manos. Un grupo de vecinos una mañana, al alba, llegó frente a la ventana de la celda donde el trágico brujo esperaba la hora de su libertad y lo acribillaron a balazos". 8

Fernández se fundó en este hecho, que en la época alcanzó resonancia, para elaborar su pieza. De ahí el rótulo de "drama histórico contemporáneo". Los antecedentes de la fama de Moreira -que aun antes del folletín de Gutiérrez circulaba en el pueblo-, algunos escritos de Mansilla y la lectura de los escritos periodísticos de Hernández, le condujeron a idealizar también los móviles de la conducta de Solané y a imprimir cierta fuerza de alegato a su obra, inscribiéndola así en la segunda de las vertientes antes mencionadas, a través de las cuales se orientó lo gauchesco literario.

Al describir a su hétoe, Fernández presenta así a Solané: "Viste de blanco; sombrero de paja ala ancha, saco, bombacha, bota de becerro, pañuelo al cuello, poncho pampa al brazo". Diversos críticos destacan la importancia y significado de este aspecto externo del personaje. "No debemos olvidar -anota Ricardo Rojas - que Fernández era entrerriano y además militar de nuestras guerras civiles, lo cual quiere decir perito en cosas gauchescas. La estampa de Solané, tal como ahí se la presenta, recuerda al Morajú pintado en nuestros días por el artista Quirós, también entrerriano. Esa figuta ya no es la de chiripá que Eduardo Gutiérrez describiría al pintar a Santos Vega, en sus novelas del género; del propio modo que la silueta moral de Solané ya no es la de Martín Fierro, tal como por entonces Hetnández habíale pintado. Parece evidente, sin embargo, que ambos autores gauchescos hayan influído sobre Fernández en esta concepción de su tipo, y acaso en algunos episodios y en el tono general del lenguaje que para la obra emplea"."

En el drama de Fernández, Solané es presentado como una especie de redentor de los gauchos explotados por autoridades militares y civiles. Genoveva, su exnovia, ha sido casada contra su voluntad por un padre déspota. Ha enviudado y es nuevamente presionada por el padre para que, de acuerdo con sus intereses éconómicos y políticos, se una al comandante Gómez. Solané secuestra a Lelia, hijita de Genoveva, para retenerla como rehén y negociar ciertas reinvindicaciones para el gauchaje.

6 Rafael Barreda: "Memorias de un periodista de ayer" (En Diario La Razón: Buenos Aires, 26 de enero de 1926). Cita transcrita por Jorge Max Rhode en la noticia preliminar de la edición de 1925.

7 Ricardo Rojas: Un dramaturgo olvidado: Francisco Fernández y sus "Obras dramáticas". Buenos Aires, Instituto de Literatura Argentina (U.N.B.A.), 1923. (p. 19). 
La idealización de Solané se concreta dialécticamente en un monólogo de la Escena 2 da. del Primer acto, cuando se queja en términos cuyo contenido, y hasta una expresa mención, recuerdan los símbolos del poema de Rafael Obligado: Santos Vega

(Solané surge entre zarzas de la gruta. Velado el semblante, de austera y noble expresión, lo ilumina por momentos su mirada intensa, serpeando el rayo de su pupila, como en un cielo gris. La actitud del singular personaje es desolada, pero altiva y de gesto severo. Parece que le agitasen bondos pensamientos, de aquellos que bullen como el metal en un crisol, precipitando protestas airadas e imágenes penosas, cruzadas por visiones fatidicas del futuro, cunque de cuando en cuando, diluyéndose en alguna esperanza, bien que incierta o fugitiva... alma de volcán donde trabajan poderosas fuerzas recónditas. Arroja al espacio un abogado suspiro a la vez que alza los brazos al horizonte, en un amplio gesto de desolación, compasiva y de impotente amenaza.)

¡Pampa infinita!. . Comprendo tu lenguaje rumoroso y el misterio que te envuelve. iTe amo, y me inmolaré en tus aras!... Capas de esqueletos, especies y razas extinguidas se hacinan en tu inmensa necrópolis; osamentas de gauchos vienen luego llenando los osarios, sin que las corrientes poderosas de la vida se agoten en tu vientre fecundo!... iY los gauchos también serán bartidos por la ola de la evolución!... ¿Pero, a qué estuario los conducitá? ¡Misterio!... ¡Oh, pampa! ¡Llevo en mi pecho tu alma silenciosa, que entre tanto llora vibrando de Santos Vega, el mito sagrado de la leyenda gaucha!

(Toma asiento en una piedra desgajada del macizo, apoya en la misma el coda y sobre la mano la cabeza; tiende a los lejos una visual sin limiles, impregnada, como va serlo su voz, con la melant colia de la acaso irreparablemente fenecido.)

Como el ombú en la sabana, el gaucho es un solitario dentro de nuestro orden social, donde la cultura incipiente de la metrópoli lo ha abandonado... no de otro modo que un ejército deja a sus heridos, que contribuyeron la víspera a darle la victoria. . ¡ $\mathrm{Ah}$, la fraternidad solidaria, de hombres, de nacionalidades! (levantándose nervioso) ¡Oh ideal de justicia! ¡Anticípanos, pues, algunos de tus esplendores, en ésta nuestra noche de desventura!... 
La contextuación romántica de este lenguaje se compagina con la de la trama: Genoveva y Solané reanudan el antiguo idilio, pero los gauchos incendian la casa donde Genoveva, su padre Bidarte y Solané acuerdan la devolución de Lelia. Solané, con riesgo de su vida salva a Genoveva y a su hija, y se entrega a la partida militar que ha acudido. Preso Solané, Genoveva y Lelia van a visitarlo a la cárcel y a anunciarle que han pedido al Gobierno clemencia para él. Cuando queda solo, por la ventana de la celda, alguien dispara el tiro que lo mata.

El desarrollo del drama es complejo; los personajes, numerosos $y$, según las características de esta vertiente gauchesca, no faltan extranjeros inmigrantes levemente caricaturizados. Abundan, pot consiguiente, los episodios secundarios comunes al drama romántico; $y$, también, es del caso consignar que, en un pasaje del Segundo Acto, Solané desliza esta reflexión acerca del inmigrante: "Planta extraña insinuándose en la flora indígena para mezclar su polen y efectuar, en una nueva raza, la recíproca selección de la especie", pensamiento que incuba la idea desarrollada más tarde por Florencio Sánchez, en La Gringa.

Pese a que la obra nunca fue representada, es interesante pulsar la reacción de un contemporáneo del autor, frente a ella: Matías Calandrelli, prologuista del volumen de Obras dramáticas, de Francisco Fernández: "Solané es el tipo de paisano perseguido y calumniado, que no hallando justicia en los magistrados, por no perder éstos el favor de la gente acomodada, apela al recurso de la fuerza pretendiendo hacerse justicia con su puñal. Hábiles argentinos han trazado con mano maestra el carácter altivo y noble, a la vez que funesto, del legendario gaucho, del pundonoroso y leal paisano. Fijándose bien en el espíritu de Solané, se observa cierto fondo de bondad, paulatinamente borrado por la mano del tiempo, empapada en accidentes desgraciados. La regeneración del gaucho para servirse de él como de instrumento de sus venganzas personales, la bandera religiosa para cobijar con ella sus crímenes misteriosos, forman el barniz de la máscara que oculta a un hombre terrible. Hipócrita, astuto, inteligente, fuerte, valiente, tiene todas las dotes de un hombre extraordinario para fascinar a los paisanos francos y leales y llevarlos a la gloria como al martirio. El amor no satisfecho, las súplicas desoídas, el linaje despreciado, la indiferencia de los magistrados, las pretensiones a puestos superiores a las fuerzas propias son, en diferentes épocas, los móviles principales de su vida singular de crímenes y horrores. Sabido es su fin y las maldiciones que arrancó a las viudas y a las inocentes criaturas que contemplaron el umbral de sus umbrales enrojecidos con la sangre de sus padres y hermanos. El tipo ha sido tomado a lo vivo. La fiereza salvaje de Solané en los momentos de cólera, y la serena tranquilidad de 
su carácter, han sido expresados de una manera artística y verdaderamente dramática. En esta producción no dañan las ideas exageradas; sirven al contrario para llevarnos a la verdad, pues si a veces la imaginación exagera en más, suele, por el contrario, aminorar el valor de las hazañas en hombres cuyo tipo créese extinguido o forjado por poetas cuyas creaciones no preocupan ya a la calculada y positiva imaginación de sus contemporáneos". 8

Desde luego que Solané acusa notorios altibajos, tanto en lo literario como en lo teatral. Algunos de sus caracteres aparecen falseados: personajes incultos hablan como letrados; las situaciones escénicas se resuelven con técnica rudimentaria. Pero, desde el punto de vista documental, se descubren valores atendibles: representa el último hito de tanteos, en el historial del teatro argentino, antes de que éste halle su senda firme. Para Ernesto Morales, "este drama coloca a Fernández como un precursor del teatro gauchesco".9 Para Arturo Berenguer Carisomo, "filosóficamente, Solané es uno de los últimos relumbres políticos de la escisión unitaria y montonera; a la sordina se deslizan constantes dicterios contra Sarmiento por la sojuzgación de López Jordán. Fernández era entrerriano, y a todo lo largo del copioso drama se traduce su animosidad contra Buenos Aires, lo cual encierra, sin querer y por contragolpe, el tema dominante de la poesía payadoresca". ${ }^{10}$

\section{II}

El 2 de junio de 1884, en un "fin de fiesta" del Circo Hnos. Carlo, por primera vez se exhibe la pantomima Juan Moreira. Un diestro y popular payaso, hábil jinete, buen cantor y guitarrero, ágil visteador frente a un facón, encarna al protagonista y produce un hecho de significación en la evolución del teatro gauchesco y del teatro nacional argentino. Pero el acierto de José J. Podestá, también conocido como "Pepino, el 88", no es un hecho casual, por una parte, en sus entradas de clown, pulsando temas de actualidad, remedando tipos extranjeros o cantando estilos y vidalas, tenía muy registrados gustos y reacciones del público; por otra, sabía bien cómo, en el ambiente porteño, había una saturación social en torno del gaucho, canalizable en elegía y alegato; también una

8 Matías Calandrelli: "Próloga" en Obras dramáticas de Francisco Fernández. Buenos Aires, Casavalle, 1881 (p. XVI).

9 Ernesto Morales: obra citada (p. 164).

10 Arturo Berenguer Carisomo: Las ideas estéticas en el teatro argentino. Buenos Aires, Instituto Nacional de Estudios de Teatro, 1947. (p. 332). 
saturación crítica que movía discusiones sobre la legitimidad cultural de las expresiones gauchescas.

Desde las tempranas composiciones de Hidalgo y Godoy; desde algunas páginas de Facundo; a través de las letrillas de Ascasubi; en ciertos capítulos de Una excursión a los indios ranqueles, de Lucio Mancilla; de los escritos periodísticos de Hernández, se venía documentando el desaprovechamiento humano del gaucho. En 1870, Estanislao del Campo publicó su alegato Gobierno gaucho; en 1872 y 1879, Martin Fierro testimonió injusticias de trato y levantó su protesta reinvindicatoria. Agréguese al cuadro la folletinería de Eduardo Gutiérrez, a través de Crónicas y siluetas militures, Santos Vega, Juan Cuello, Hormiga Negra, Juan Moretra y Pastor Luna, y se tendrá idea de la familiaridad del tema y de la naturalidad con que se asumía un proceso de idealización del gaucho.

Desde otro punto de vista, el incremento del caudal inmigratorio extranjero haća sentir al hombre de la ciudad el conflicto entre el primitivismo de una campaña elementalmente ganadera -ámbito del gauchoy las posibilidades del progreso y la intensificación de los cultivos agrícolos; al mismo tiempo que las últimas expediciones al desierto contra los indios, traían nuevamente al primer plano de atención las virtudes legendarias del gaucho al servicio de la patria.

Todo ello contribuyó a la saturación temática, la cual, junto con otros factores (hallazgo de un guión dramático, intérpretes adecuados, simpatía popular, coincidencia de aspiraciones, viejos anhelos de plasmar una dramática inconfundiblemente local y apoyo de la crítica), concretarán el impulso de un teatro vernáculo.

En Sociología del teatro argentino he caracterizado Juan Moreira como verdadera "fiesta teatral". Con este mimodrama, Argentina pudo ofrecer uno de los pocos ejemplos de teatro popular, en el cabal sentido de "fiesta", aparecidos en la moderna dramaturgia universal. En la ciudad, la pantomima provocó un fenómeno de curiosidad por el espectáculo que, en sucesivas reposiciones, orientó toda clase de público hacia las graderías circenses, en verdadera identificación de personajes ficticios y espectadores; la completa instalación de éstos en lo ficcional, superadas todas las convenciones del arte, de niveles sociales y económicos.

Juan Moreira fue - como Martín Fierro, como Solané, como la serie de piezas gauchescas que de él se desprenden- fruto tardío del romanticismo social. Su escenificación coincidió con el fin de las luchas civiles que dividían políticamente a los argentinos de la ciudad y de la campaña; con la marea creciente de contingentes inmigratorios que desalojaban al gaucho nómade, reacio al progreso, a las leyes y al orden; con la transformación de compadres y delincuentes - como Moreira y Solané- en 
hétoes marginados e idealizados, capaces de líricas hazañas o de oscuros crímenes.

Juan Moreira, matón y guardaespaldas de Adolfo Alsina, en el folletín de Gutiérrez y en la pantomima, es presentado como gaucho leal y valiente, amante de su mujer e hijo; a quien persiguen las injusticias: lo estafa un pulpero italiano, un juez pretende a su "china". Hiere y mata en legítima defensa; se brinda noblemente en ayuda de débiles y necesitados. Finalmente, acosado por una partida policial, cuando se disponía a huir es herido a traición por un oculto sargento y muere.

La. adaptación inicial del folletín de Gutiérrez se debió a José J. Podestá. Las acciones fueron mimadas y el espectáculo fue enriquecidọ con elementos folklóricos: bailes, cantos, habilidades ecuestres y con las armas. El traslado se efectuó a regañadientes del novelista $y$, tal vez -frente a otras experiencias semejantes, incluidas las de Martín Fierro-, esta resistencia sea un factor que mueva a reflexión. Don años más tarde, sobre el primitivo guión pantomímico, y esta vez con la inter. vención de Gutiérrez, se le confiere un texto a Juan Moreira. Siempre en carpas circenses recorre el país, Uruguay y Brasil. Nace, consiguientemente, la necesidad de un repertorio afín y nuevos autores ofrecen nuevas obras gauchescas sobre el patrón de éxito probado.

En 1889, el Dr. Elías Regules (h.) adapta para el espectáculo circense Martín Fierro y escribe piezas originales, como El entendo y Los gauchitos. El periodista Luis Mejias, en 1890, adapta Juan Cuello, novelón de Eduardo Gutiérrez. Abdón Arósteguy, en 1892, escribe Julián Jiménez; Vicente Pérez Petit, en 1894, compone Cabarde y Tribulaciones de un criollo; Juan Carlos Nosiglia, traslada Santos Vega. En 1896, Martiniano Leguizamón estrena la égloga Calandria.

La revitalización del teatro gauchesco -obra conjunta de autores argentinos y uruguayos - ha fortalecido la vida teatral criolla $\mathrm{y}$, con Calandria, casi al borde del nuevo siglo, también queda señalada la inminente transformación del teatro gauchesco en "teatro tural".

\section{III}

Importa ahora, puesto que ha sido propuesto como eje de este ensayo, intercalar una serie de datos digresivos acerca de la suerte corrida por Martín Fierro en su efímera vida teatral, transformado en espectáculo dramático. Debo anticipar que sólo conozco tres versiones dramatizadas del poema de Hernández: la realizada para la empresa circense de los Podestá, por el poeta uruguayo Elías Regules (h.), en Montevideo, en 
1889; la de José González Castillo, llevada a cabo en Buenos Aires, en 1915; y la escenificación, a modo de "cantata", intentada por Juan Carlos Ghiano, en Buenos Aires, en 1972.

Cada una de estas versiones obedeció a razones distintas: interés comercial por seguir explotando una vena redescubierta, en el primer caso; el hecho de una simpatía ideológica, en el segundo; un propósito conmemorativo de homenaje al poeta creador, en el tercero. Los tres traslados han tenido en cuenta los vagos perfiles de latencia dramática subyacentes en los antecedentes gauchescos literarios, pero ninguno se ha planteado - - práctica y epistemológicamente- la indispensable alteración de estructuras profundas requerida.

En alguna oportunidad, he estudiado en Martin Fierro el carácter predramático y de inconfundible concepción juglaresca: una voz narra. dora, que alterna estilo directo e indirecto; que mima y asume circunstancialmente otras voces secundarias; la "rueda" de oyentes; los zigzagueos de la temporalidad. ${ }^{11}$ Por el asunto desarrollado, por el tratamiento elegido para el mismo por Hernández, Martín Fierro, desde el momento de su concepción y, firmemente, a cada paso de su elaboración, incuba, desarrolla y confirma la tendencia hacia el epos. Declarada o in mente, Hernández tiene siempre presente la imagen de la "rueda", del fogón gaucho, del corro en la pulpería. Y una de sus más hábiles estratagemas de poeta, tal vez sea el haber logrado que cada uno de los lectores del poema, se sienta incorporado al círculo de receptores. A diferencia del folletín Juan Moreira, de estructura lineal y abundante en episodios concurrentes al sostén de la misma, en el caso de Martín Fierro mutar su condición épica a otro patrón formal implica anular elementos fundamentales de su esencia narrativa. $\mathrm{Y}$ esto ha ocurrido con los tres traslados que comentaré: ninguno de ellos logró proyectar escénicamente los efectos provenientes del mecanismo evocativo que opera como una de las claves estructurales del poema; ninguno recreó la imagen de la "rueda". Además, en ninguno de ellos tampoco ganó efectividad -como la ganó en el caso de Juan Moreira- el hecho de desarrollar y conferir presencia directa a las acciones potenciales contenidas en el texto literario.

Según Vicente Rossi, "en matzo y abril de 1890, los Hermanos Podestá estrenan en La Plata (Argentina), la segunda obra criolla: Martín Fierro, arreglo del Dr. Elías Regules". Los Regules, padre e hijo, eran, en el Uruguay, entusiastas cultores del arte nativista. Cuando, a fines de 1889, el Circo Podestá-Scotti llega a Montevideo y presenta el espectáculo de Juan Moreira, Elías Regules, padre, sugiere a los intérpretes la incor-

11 Raúl H. Castagnino: "Elementos referenciales básicos para interpretar Martín Fiemo", (en The gaucho Martín Fierro, Albany, SUNY Press, 1973). 
poración al mismo del "Pericón" como danza de mayor visualidad teatral, cuyas figuras les explicó, dirigiendo la coreografía. Elías Regules, hijo, (1860-1929), médico prestigioso y poeta inclinado a la veta folclórica, a raíz de sus contactos con el drama circense, afirmó una vocación teatral criollista, intentando la primera dramatización conocida de Martín Fierro y componiendo luego piezas gauchescas originales.

El manuscrito de la adaptación de Regules, en copia realizada en 1933 por el apuntador Eusebio del C. Núñez, fue propiedad de Juan C. Maubé, y se conservaba posteriormente en el Instituto de Literatura Argentina, de la Facultad de Filosofía y Letras de Buenos Aires. El adaptador, para la representación, subrayó las acciones configuradoras de los sufrimientos del gaucho perseguido y las injusticias padecidas. Pepe Podestá, en sus Memorias, a propósito de su recuerdo agradecido para con Regules, sienta este testimonio: "El Dr. Regules se inició en su colaboración dramática con un acertado arreglo escénico de Martín Fierro, cuyo libreto me entregó con la siguiente dedicatoria sentida y sencilla:

Este Fierro que aquí ve no es Hernández todo entero, algo me toca, y yo quiero dedicar ese algo a usted.

$Y$ aunque demasiado sé que Moreira es muy ladino, deseo que con buen tino y con empeño prolijo nos dé un Fierro digno hijo de Hernández y de Pepino". ${ }^{12}$

La dramatización de Regules, como ocurrirá también con la posterior de José González Castillo, añadió de su cosecha elementos dramáticos y texto para hacer factible la acción escénica; acción que en el relato original de Hernández opera a través del estilo narrativo indirecto. El desarrollo teatral, en Regules, se extendió en dos actos y diez cuadros. El historiador Walter Rela estima que esta versión "no soslayó el aspecto social que impregna al protagonista de la vida feliz en la estancia, maltratado después en el fortín de la frontera con los pampas, y al matrero que jura, después de la huída de ese infierno, ser más malo que una fiera... Regules se ciñó el texto original consiguiendo una dignisima equivalencia con las agudas sextinas de Hernández". ${ }^{13}$ Lo de ceñirse

12 Vicente Rossi: Teatro Nacional Riopiatense. Río de la Plata, 1910. (p. 80).

1.3. Walter Rela: Historia del teatro uruguayo. Montevideo, Ediciones de la Banda Oriental, 1969. (p. 45). 
al texto original apuntado por Rela se refiere a la síntesis argumental. El propio Regules anticipó que no da "Hernández todo entero" y que en la adaptación teatral "algo me toca". Por otra parte, en las historias que estudian el lapso de vida circense de los dramas gauchescos, no se consignan ecos de trascendencia ni se registra su asidua presencia en carteleras.

El teatro criollo, cumplido su ciclo del picadero, ascendió a los escenarios ciudadanos. Otros intérpretes, otras temáticas e intereses dieron oportunidad del ejercicio dramático a un grupo de autores que pulieron su oficio de creadores y se familiarization con los secretos del arte teatral. Habrá que esperar hasta 1915 para localizar el nuevo intento de traslado genérico del poema de Hernández, llevado a cabo -por sugerencia del actor y director Elías Alippi-, por el dramaturgo argentino José González Castillo.

Con criterio de experto hombre de teatro, González Castillo desmiembra la estructura original del poema y la rearma para la operatividad escénica. En la concepción hernandiana, Fierro es actante, testigo e informante a la vez. En la estructura teatral propuesta por González Castillo es sólo actante, alguna vez oyente pasivo; y pasan a la condición de informantes o de actantes circunstanciales, personajes innominados del poema, en cuyos labios se actualizan los textos informativos originales. Además, el adaptador añade prosa y verso de su cosecha.

González Castillo no se arredró ante el problema de la temporalidad del poema. Sabido es que, en La vuelta, Hernández alteró la cronología lineal con el truco de los "raccontos". El adaptador enfrentó el problema de los avances temporales de la acción central, paralelos coincidentemente en el poema y en la dramatización hasta el final del cuadro séptimo de ésta. Con el Canto XII (2da. Parte) -donde se relata el reencuentro de Fierro con sus hijos y con Picardía - la narración hernandiana marca una dirección temporal distinta: el tiempo retrocede y el lector se entera de lo ocurrido a los jóvenes durante los diez años de ausencia de Fierro. Es decir que, con técnica de flasbback, desde el punto de vista narrativo de estos nuevos relatores, vuelven a transcurrir los diez años que ya se sabe cómo fueron para Fierro.

González Castillo intenta resolver en el escenario esta dificultad, pero, teatralmente, la solución aparece forzada, porque no justifica a los nuevos personajes. Esta versión aprovecha todos los personajes de primer plano del poema: Fierro, Cruz, el hijo menor de Fierro, el moreno payador; opaca al hijo mayor, minimiza a Vizcacha, ignora a Picardía. Da, en cambio, mayor intervención dramática a una serie de anónimos segundones: juez, alcalde, pulpero, napolitano, inglés, etc. Como en la adaptación de Regules, a través de ellos también se animó lo pintoresco, la nota 
cómica, teniendo en cuenta la necesidad de aprovechar elencos numerosos y heterogéneos.

A diferencia de los anteriores adaptadores que intentaron la teatralización del poema, la versión de Juan Carlos Ghiano asume forma de "cantata". Diversos relatores, en primer plano, comunican la parte expositiva; mimos, desde segundos planos, en un carácter de ballet estilizado, corporifican algunos de los momentos de acción. Alguna canción intercalada, el enfrentamiento directo de la payada final constituyen los escasos elementos de realidad vital incorporados. La ausencia de detalles pintorescos y el apareamiento de aquellos escasos elementos realistas con abundantes factores expresionistas restan unidad de estilo al conjunto. Escénicamente no se contagia la fuerza del poema; su contexto evocativo se diluye y la frialdad de un montaje excesivamente racionalizado subraya la hibridez de esta versión.

En las tres versiones, lo que fundamentalmente se nota ausente es aquel elemento no declarado en el poema, aunque de latente presencia en función de los distintos puntos de vista narrativos operantes: la sugestión de la rueda de oyentes; esa congregación invisible -lo que Martínez Estrada llamó personajes inadvertidos-, presunta destinataria directa de la relación de Fierro. El poema está abierto hacia ella y, desde ella, a los lectores de todos los tiempos, como recipiendarios segundos.

Queda, como conclusión visible, la desafortunada vida teatral de Martín Fierro. Se lo adapta, en los días del circo, como obra unánimemente conocida y aceptada, para seguir explotando el filón del renacido teatro gauchesco. Su éxito es muy relativo. Otro tanto ha ocurrido con la versión de González Castillo, repetida sólo en 1942, en ocasión de que Elías Alippi ocupó circunstancialmente la dirección del Teatro Nacional de Comedia de Buenos Aires. Y la versión de Juan Carlos Ghiano sostuvo una breve temporada, en la misma sala, como homenaje oficial en el año del centenario de la Primera Parte del poema.

Martín Fierro, como obra teatral, no homologó el brillante destino del poema ni tuvo incidencia en la evolución del teatro argentino. Creo que si se compara la influencia de Juan Moreira y la de Martin Fierro en el teatro, habrá que convenir la gravitación indiscutible del primero. Desde luego que, además de los hechos visibles, hay razones intrínsecas que explican ese resultado: descontada la cuestión básica de que en Martin Fierro hay elementos que - pese a su índole preteatral y jugla. resca- son intransferibles (por ejemplo, el clima de la "rueda" de oyentes), no se olvide que Juan Moreira pasó del folletín al picadero por la audacia de un saltimbanqui y payaso con larga experiencia acerca 
de gustos populares, de las posibilidades de llegar a los espectadores, y con no mucha escrupulosidad estética. ${ }^{14}$ Por otra parte, la prosa folletinesca de Gutiérrez ya había consumado una primera transformación de la realidad histórica en el nivel del gusto popular. La responsabilidad de fidelidad era menor; la pantomima of recia suficiente elasticidad y cabía agregar cuanto elemento folclórico se tenía a mano. Martín Fierro, en cambio, ofrece la sobriedad y rigidez de un texto poético. Intentan su trasvasamiento, sucesivamente: un poeta, un dramaturgo y un crítico. Los tres se sienten constreñidos por el respeto a un texto conocido y consagrado, por lo tanto innamovible. Escrupulosamente ensayaron ins. talarlo en otra estructura genérica $y$, los tres, quedaron a mitad camino.

Cumplido el ciclo de triunfo en los picaderos circenses, los ex-saltimbanquis convertidos en actores saltan a los escenarios ciudadanos. A la herencia del romanticismo social que ellos divulgaron con las carpas trashumantes, se unen en esta nueva etapa las influencias europeas del realismo y el naturlismo, los contenidos socialistas de sus ideologías. También el teatro gauchesco se irá paulatinamente desdibujando en las formas y temas de "teatro rural", acorde con el proceso socioeconómico que, en la realidad, marca el ocaso del tipo humano del gaucho. Nuevos problemas, temas y personajes crecerán con un nutrido repertorio, cuya

\footnotetext{
14 Cuando hablo de "audacia" y experiencia popular de "Pepino el 88" no lo hago en sentido peyorativo. Simplemente quiero significar que antepuso el "oficio" por sobre el escrúpulo estético. El caso se tepite constantemente en la historia de los espectáculos masivos y, en particular, con relación a la etapa circense del teatro gauchesco. Por ejemplo, en El circo criollo he documentado una pintoresca anécdota referida por un autor de la época: Eugenio Gerardo López. Recuerda dicho autor, en un artículo que publicó en el diario La Razónz (16 de abril de 1949): "El empresario Rafetto me pidió cierta vez una obra para estrenarla como epílogo del espectáculo de pista. "Quiero - me dijo- un drama terrible. Es lunes y lo estrenaremos el jueves. Te pagaré sesenta pesos, pero me tienes que matar todos los milicos que puedas". El primer acto le encantó; al fin del segundo acto en que moría el héroe noble, Rafetto torció el gesto y dijo que no podía ser. Le argüí que así lo exigía la acción de la pieza. Pero como él insistiera tanto y yo necesitara los sesenta pesos, no atreviéndome ya a rehacer el drama, opté por un ardid: en el acto tercero hice aparecer como que la muerte ocurrida en el segundo había sido simulada. Rafetto, loco de contento, me pagó diez pesos más "por haber resucitado al muerto". Salí huyendo. Pero aún me gritó el hombre: "Eh, que me lo tienes que dar con apoteosis de angelitos y otras figuraciones..." $\mathrm{Y}$ más adelante menciona López cómo, en otra ocasión, Rafetto le pedía a un actor, Hénault: "esta noche mátame dos milicos". "Y se instalaba en primera fila para fiscalizar cómo se cumplía su deseo. $Y$ cuando Hénault estaba en vena aumentaba la carnicería. En tales casos su empresario lo llevaba a la cantina y le pagaba un cognac por cada milico que habia apuñaleado en la ficción". (pp. 72, 73).
} 
realización teatral se encierra en el espacio "a la italiana", con el confinamiento infranqueable de la "cuarta pared".

En las formas primeras del teatro gauchesco, el protagonista era el sér nomade que se movía en la infinitud de las llanuras. Transportaba consigo sus bienes e implementos: pilchas, distracción (guitarra, mate y caña), armas. El caballo era compañero, vehículo para las travesías en desiertos inconmensurables, orgullo de sus lujos y de sus habilidades ecuestres. No le arredraban distancias, inclemencias, enemigos ni obstáculos. Asumía su libertad y la defendía a toda costa. En las formas evolucionadas del teatro rural se esfuma el héroe mítico al tiempo que queda testimoniada la transformación del medio: advenimiento de la civilización agrícola, con el paisano o peón, de a pie; con la necesidad de seguridades para las tareas labrantías, la industrialización ganadera en los sementales, el mestizaje y cuidado científico de las especies; con una no enseñada exigencia de integración social.

El teatro rural documenta la nueva fisonomía de la campaña argentina: estancias alambradas, parcelación de tierras, chacras y colonias, cultivos, granja. El gaucho convertido en paisano trabajador, como Calandria; en peón, como Manuel, el de La piedra de escándalo, de Martín Coronado; el colono enriquecido, como patrón, según se documenta en La gringa; en ;Al campo!, de Nicolás Granada; o como arrendatarios esquilmados por terratenientes insensibles, según le ocurte al Don Pietro de Madre tierra, de Alejandro Berrutti; a Chango, en El patrón del agut, de Gustavo Caraballo. Otras formas de prepotencia, opresión y sumisión también se reflejarán en este nuevo ciclo: la que señala la decadencia del criollo, en Barranca abajo de Florencio Sánchez; la que denuncia la usurpación de tierras a legítimos dueños y alienta la consiguiente rebeldía libertaria, en Las víboras, de Rodolfo González Pacheco; la de innobles caudillismos de políticos lugareños incscrupulosos, como en El señor maestro, de José J. Berrutti.

Este teatro rural se corresponde con la realidad campesina ulterior a Martín Fierro. Y si en éste, con el tono elegíaco de sus estrofas finales, se advierte la necesidad de cambio en el destino del gaucho, se propugna para él humana consideración y trato, la convivencia de integrarlo en un proceso de transformación social; la evolución posterior del teatro gauchesco en teatro rural documenta etapas, alternativas, fortuna e infortunios de esa transformación. Aunque las historias generales del teatro argentino y algunos estudios parciales han acumulado información y datos acerca de ambos, está aún por realizarse la investigación exhaustiva de tal proceso, desde el punto de vista de las incidencias ideológicas. de las connotaciones socioeconómicas. 
Antes de Martin Fierro, un teatro primitivo gauchesco dio los primeros testimonios de una realidad campesina de existencia paralela a la realidad urbana; a veces ignorada por ésta, siempre menospreciada. Durante el siglo Xix, la literatura gauchesca general conservó latente una contextuación de oralidad, ricos elementos de ascendencia juglaresca y preteatral, reconocibles aun en sus manifestaciones periodísticas y epistolares. Juan Moreira, en el picadero circense, amalgamó ambos factores y proyectó nuevos derroteros teatrales, de ulterior trascendencia en la dramática nacional argentina, tanto campesina como urbana. Martín Fierro, sin ninguna influencia en el desarrollo posterior del teatro, en cambio creció su magnitud épica hasta enseñorarse como "el" poema nacional argentino por antonomasia.

Raúl H. Castagnino

State University of New York.

Albany. 